\title{
The effects of onion consumption on treatment of metabolic, histologic, and inflammatory features of nonalcoholic fatty liver disease
}

\author{
Hadi Emamat ${ }^{1}$, Forough Foroughi ${ }^{2}$, Hassan Eini-Zinab ${ }^{1}$, Mohsen Taghizadeh ${ }^{3}$, Marjan Rismanchi ${ }^{1}$ \\ and Azita Hekmatdoost ${ }^{1 *}$
}

\begin{abstract}
Background: The aim of this study was to evaluate the effects of onion powder consumption on treatment of Non-alcoholic Fatty Liver Disease (NAFLD) in an experimental model of disease.

Methods: Sprague-Dawley rats were fed high-fat (HF) diet for seven weeks to induce the NAFLD. Then, they were treated by either the same diet (HF), or high-fat diet plus $7 \%$ onion powder (HF + onion), or chow diet (control), or chow diet plus $7 \%$ onion powder (control + onion)ad libitum for four weeks. Serum levels of fasting glucose, triglyceride, cholesterol, liver enzymes, insulin, and hepatic tumor necrosis factor-alpha (TNF-a) gene expression were determined. Hepatic histology was examined by Hematoxylin and Eosin stain.

Results: Dietary food intakes and weigh gain were significantly more in animals fed control + onion diet in comparison to the other groups. Animals fed control or control + onion diet had significantly lower plasma levels of hepatic enzymes, lipid profile, glycemic indices, and hepatic TNF-a gene expression as compared with HF diet fed groups; however, there was no significant difference in the histopathologic features of NAFLD among different groups.
\end{abstract}

Conclusion: Our results indicate that onion consumption can be effective in NAFLD management when it is combined with a healthy diet.

Keywords: Onion, Nonalcoholic fatty liver disease, Treatment, Body weight, Experimental model, Quercetin

\section{Background}

Non-alcoholic fatty liver disease (NAFLD), as the most common liver disease, is becoming anoutstanding public health concern in the world [1]. NAFLD is strongly associated with the features of metabolic syndrome such as hyperglycemia, central obesity and dyslipidaemia [2]. It is also associated withincreased risk of all-cause mortality, contributed by liver relateddeaths as well as nonliver related causes such as malignancy,diabetes, and cardiovascular disease [1]. Although the beneficial role of

\footnotetext{
* Correspondence: a_hekmat2000@yahoo.com

${ }^{1}$ Department of Clinical Nutrition and Dietetics, Faculty of Nutrition Sciences and Food Technology, National Nutrition and Food Technology Research Institute, Shahid Beheshti University of Medical Sciences, Tehran, Iran

Full list of author information is available at the end of the article
}

diet and some dietary supplements on NAFLD treatment have been shown recently [3-9], no consensus has yet been achieved. Thus, finding effective therapies are a research priority to reduce the anticipatedburden of liver diseases [10].

Onion has the potential properties in amelioration of inflammation, hyperglycemia andhyperlipidemia [11, 12]. Its high content of flavonoids [13], makes it as a great source of antioxidants and anti-inflammatory agent [14]. It seems that all of these properties can help in treatment of NAFLD. Therefore, the purpose of thepresent study was to examine the effects of oraladministration of onion powder on hepatic and serum features of NAFLD in an experimental model of disease. 


\section{Methods}

\section{Animals and diets}

Twenty-four male Sprague-Dawley rats (weighted 120150 gram), which were purchased from Pasteur Institute (Karaj, Iran), were individually housed individually in wire bar-floor cages. The animals were allowed one week of acclimatization in a standard environment at $22{ }^{\circ} \mathrm{C}$, $50 \%$ humidity and 12-h light/dark cycles with free access to food and water. During the first week, all animals were fed a standard laboratory chow diet (Pasture Institute, Iran) and afterwards they fed a high fat, high sugar diet in seven week for induction of NAFLD [15]. Then, treatment phase was designed for four weeks. Body weights (BW) in grams were recorded on arrival and every two week thereafter. Food intakes were also monitored twice a week. In treatment phase,the animals were randomly assigned to four groups : first group fed a standard chow diet (control group) with $10 \%$ of energy derived from fat, $30 \%$ from protein, and $60 \%$ from carbohydrates, second group fed a high-fat, high sugar diet (HF group) with $59 \%$ of energy derived from fat, $30 \%$ from carbohydrates, and $11 \%$ from protein, the third group fed high-fat, high sugar diet added $7 \%(w / w)$ onion powder ( $\mathrm{HF}+$ onion group) with $59 \%$ of energy derived from fat, $31 \%$ from carbohydrates, and $10 \%$ from protein and finally fourth group fed chow + onion diet (control + onion) with $10 \%$ of energy derived from fat, $62 \%$ from carbohydrates, and $28 \%$ from protein. Groups were fed ad libitum. Onion powder was prepared according to the methods used by Hamauzu et al. [16]. The diets were prepared weekly and stored as vacuum packed (500 g) at $-20{ }^{\circ} \mathrm{C}$. Packs taken for use were thawed in the refrigerator at $4{ }^{\circ} \mathrm{C}$. The food was offered daily at the beginning of the dark phase, and the remains were weighed and removed after $48 \mathrm{~h}$.

After eleven-week feeding period, animals were killed in the overnight fasting state by exsanguination (under light pentobarbital anesthesia). All animal procedures were carried out in accordance with the National Nutrition and Food Technology Research Institute (NNFTRI). The study protocol was approved at NNFTRI ethics committee with ethics code of NNFTRI 1393-568.

\section{Tissue and blood preparation}

Blood samples were collected in heparinized tubes; then, centrifuged ( $3500 \mathrm{rpm}, 15 \mathrm{~min}$, at $6{ }^{\circ} \mathrm{C}$ ) to obtain the plasma. Fasting plasma glucose was measured immediately, and the remaining samples were kept at $-80{ }^{\circ} \mathrm{C}$ before biochemical analysis.

After blood sampling, the livers were excised, washed with cold physiologic saline (0.9\%), and dried. One lobe of each liver tissue was preserved in $10 \%$ bufferedformalin solution for histopathologic examination. Other liver samples (200 $\mathrm{mg}$ ) were placed in liquid nitrogen tank, and then kept at $-80{ }^{\circ} \mathrm{C}$ for gene expression evaluation [17-20].

\section{RNA extraction and quantitative RT-PCR}

Total RNA was purified using RNeasyPlus Mini Kits (Qiagen) according to the manufacturer's instructions and cDNA synthesized with Superscript II reverse transcriptase (Invitrogen). Quantitative real-time PCR was performed using the Bio-Rad Laboratories MJ mini Opticon Real-Time PCR System, using IQ SYBR Green Supermix (Bio-Rad).

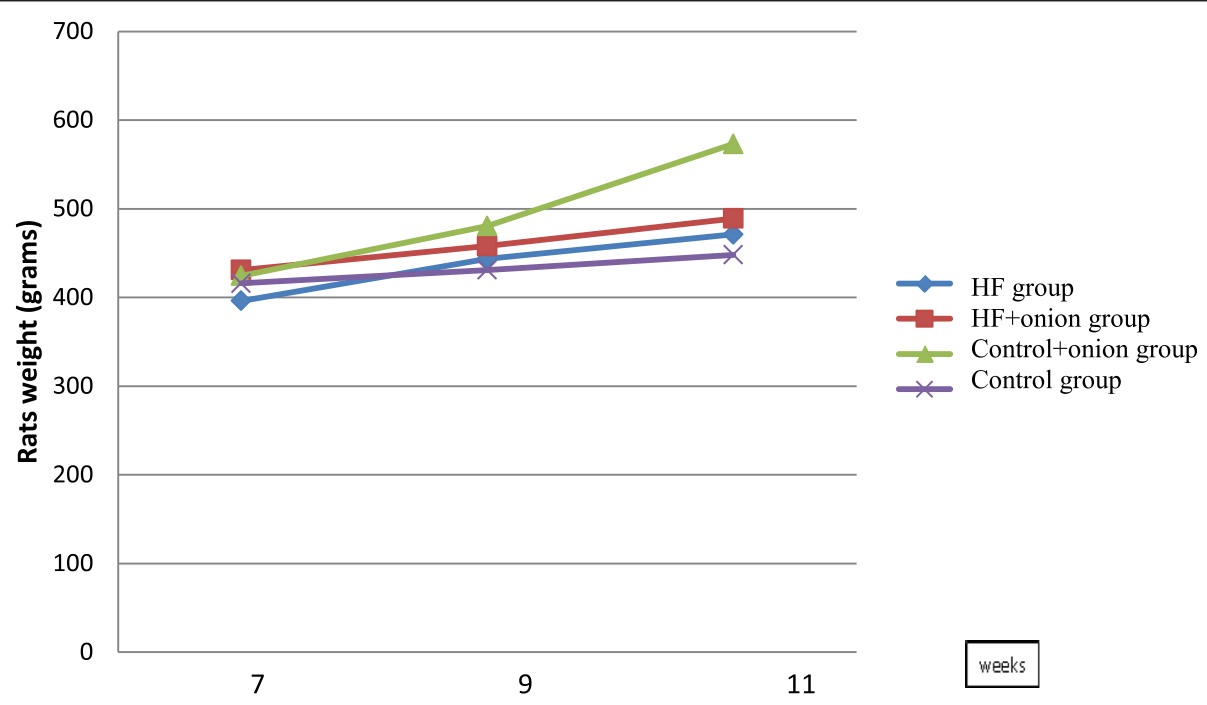

Fig. 1 Animal weights in different groups during study. Weight gain was statistically different between four groups $(P<0.05)$. Weight gain was significantly more in control + onion group than the other three groups $(P<0.05)$. HF group weight gain was more than control group $(P=0.002)$. Other differences were not statistically significant between groups 


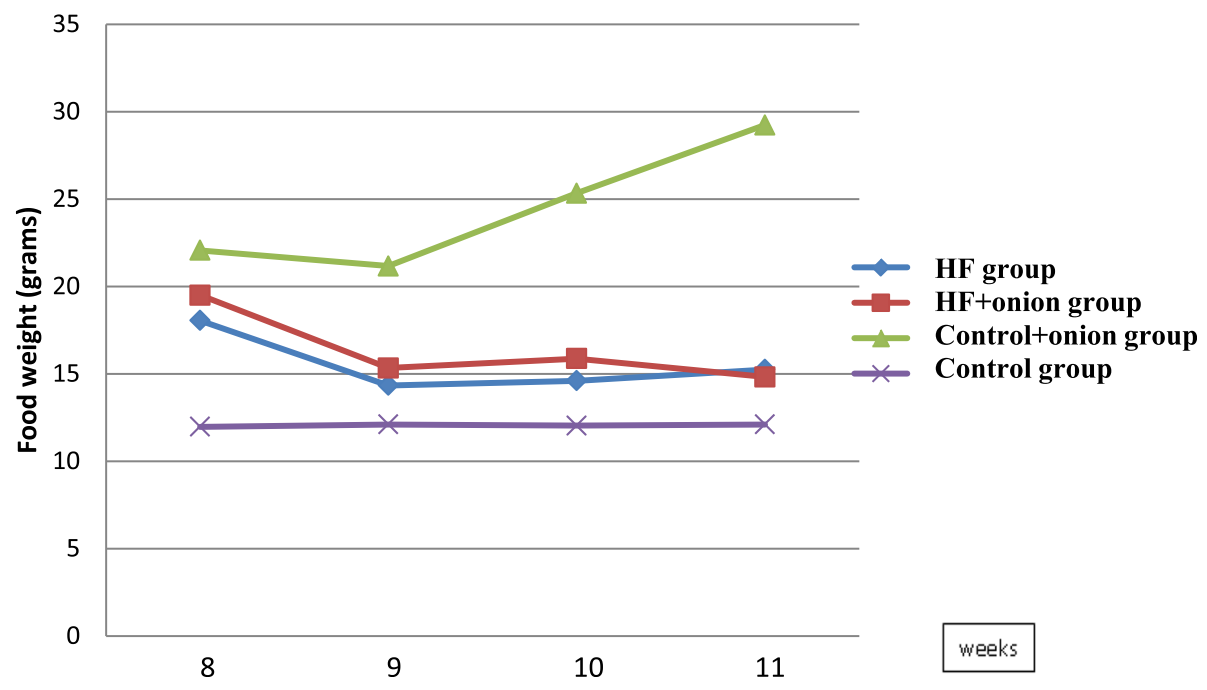

Fig. 2 Food intakes in different groups during the study. Food intake was significantly different between four groups in every week $(P<0.01)$. Food intake was significantly more in control + onion group than other three groups $(P<0.01)$. Food intake in control group was less than food intake in $\mathrm{HF}$ group and $\mathrm{HF}+$ onion groups $(P<0.01)$. No difference was seen between $\mathrm{HF}$ and $\mathrm{HF}+$ onion group in food intake

The PCR mix contained $2 \mu \mathrm{l}$ cDNA, $1 \mu \mathrm{l}$ of the appropriate forward and reverse primers, and $2 \mu \mathrm{L}$ SYBR Green PCR Master mix in a total volume of $25 \mathrm{~mL}$. PCR consisted of 50 cycles of denaturation at $94{ }^{\circ} \mathrm{C}$ for $30 \mathrm{~s}$, annealing at melting temperature $(\mathrm{Tm})$ for $30 \mathrm{~s}$, and extension at $72{ }^{\circ} \mathrm{C}$ for $60 \mathrm{~s}$. Primer sequences for each target gene, their source as well as their optimal PCR annealing temperatures are as follows: GAPDH forward primer 5'-GTGCTGAGTATGTCGTGGAGTCTA-3' and reverse $5^{\prime}$ - TCTCGTGGTTCACACCCATCAC -3' (Tm $\left.60{ }^{\circ} \mathrm{C}\right)$, and TNF- $\alpha$ forward primer 5 ' - ACT GAA CTT CGG GGT GAT TG -3 ' and reverse $5^{\prime}$ - GCT TGG TGG TTT GCT ACG AC $-3^{\prime}\left(\operatorname{Tm} 60{ }^{\circ} \mathrm{C}\right)$. Primer specificity was confirmed from the product size by agarose gel electrophoresis and the specificity of the PCR products checked by melt curve analysis.

\section{Biochemical assessments}

Plasma concentrations of alanine aminotransferase (ALT), and aspartate aminotransferase (AST) were measured using optimized UV at $340 \mathrm{~nm}$, and insulin concentrations were measured using a rat insulin radioimmunoassay kit at $4{ }^{\circ} \mathrm{C}$ (Linco Research Inc, St Charles, MO). Plasma glucose and triglyceride were measured colorimetrically, Gamma glutamyltransferase (GGT), and Alkaline phosphatase (ALP) assessed photometrically, total Cholestrol, HDL, and LDL cholesterol

Table 1 Serum level of hepatic enzymes, lipid and glycemic profiles in different groups at the end of study

\begin{tabular}{|c|c|c|c|c|c|}
\hline & $\begin{array}{l}\text { HF group } \\
\text { (median (IQR)) }\end{array}$ & $\begin{array}{l}\mathrm{HF}+\text { onion group } \\
\text { (median (IQR)) }\end{array}$ & $\begin{array}{l}\text { Control group } \\
\text { median (IQR)) }\end{array}$ & $\begin{array}{l}\text { Control + onion group } \\
\text { (median (IQR)) }\end{array}$ & $P$-value ${ }^{d}$ \\
\hline $\mathrm{ALT}(\mathrm{IU} / \mathrm{L})$ & $57(47.2-75.7)^{b, c}$ & $62.5(47.5-76.7)^{c}$ & $50(29.2-62.7)^{a, b, c}$ & $39(30.7-49)^{a}$ & 0.05 \\
\hline AST(IU/L) & $34(28-50)^{b}$ & $25(19.5-35) a, b, c$ & $21.5(18.5-33)^{a, c}$ & $23.5(18.7-31.2)^{c}$ & 0.1 \\
\hline GGT (IU/L) & $3.9(3.4-4.6)^{\mathrm{a}}$ & $2.9(2.2-3.8)^{a}$ & $3(2.7-3.2)^{a}$ & $2.8(2.4-3.4)^{\mathrm{a}}$ & 0.1 \\
\hline ALP (IU/L) & $890(754.7-1002)^{a}$ & $937(812-1098)^{a}$ & $468(411-542)^{b}$ & $479(395-635)^{b}$ & 0.002 \\
\hline Glucose (mg/dl) & $194(160-215.7)^{b}$ & $163(134.7-189.5)^{a, b, c}$ & $150.5(135.2-168.5)^{a, c}$ & $133(118.5-151)^{c}$ & 0.04 \\
\hline Insulin (pmol/l) & $465(402-512)^{a}$ & $444(392-506)^{a}$ & $192(176-219)^{b}$ & $179(165-202)^{\mathrm{b}}$ & 0.01 \\
\hline TG $(\mathrm{mg} / \mathrm{dl})$ & $135(118-145)^{a}$ & 124.5 (114.2-149) a,b & $102(88.5-121.5)^{b, c}$ & $83(70.2-93.2)^{c}$ & 0.001 \\
\hline Cholesterol (mg/dl) & $125(110.7-138)^{a}$ & $122.5(116-139.7)^{a}$ & $109.5(98-116)^{b}$ & $104(96-118.5)^{b}$ & 0.03 \\
\hline HDL-C (mg/dl) & $45.5(31.5-53.5)^{\mathrm{a}}$ & $37.5(29.2-43)^{a}$ & $41.5(36.5-52.2)^{a}$ & $50.5(43.7-56)^{a}$ & 0.1 \\
\hline LDL-C (mg/dl) & 56.7 (36.7-75.6) & $62.5(51.2-80.4)^{b}$ & $44.9(33.3-52.5)^{a, b}$ & $39.8(33.6-50.3)^{a}$ & 0.08 \\
\hline
\end{tabular}

IQR interquartile range, $A L T$ alanine aminotransferase, $A S T$ aspartate aminotransferase, GGT gamma glutamine transferase, $A L P$ alkaline phosphatase, $T G$ triglyceride, $H D L-C$ high density lipoprotein cholesterol, $L D L-C$ low density lipoprotein cholesterol

$a, b, c$ In every row different scripts show significant difference

${ }^{\mathrm{d}}$ Kruskal-Wallis test 


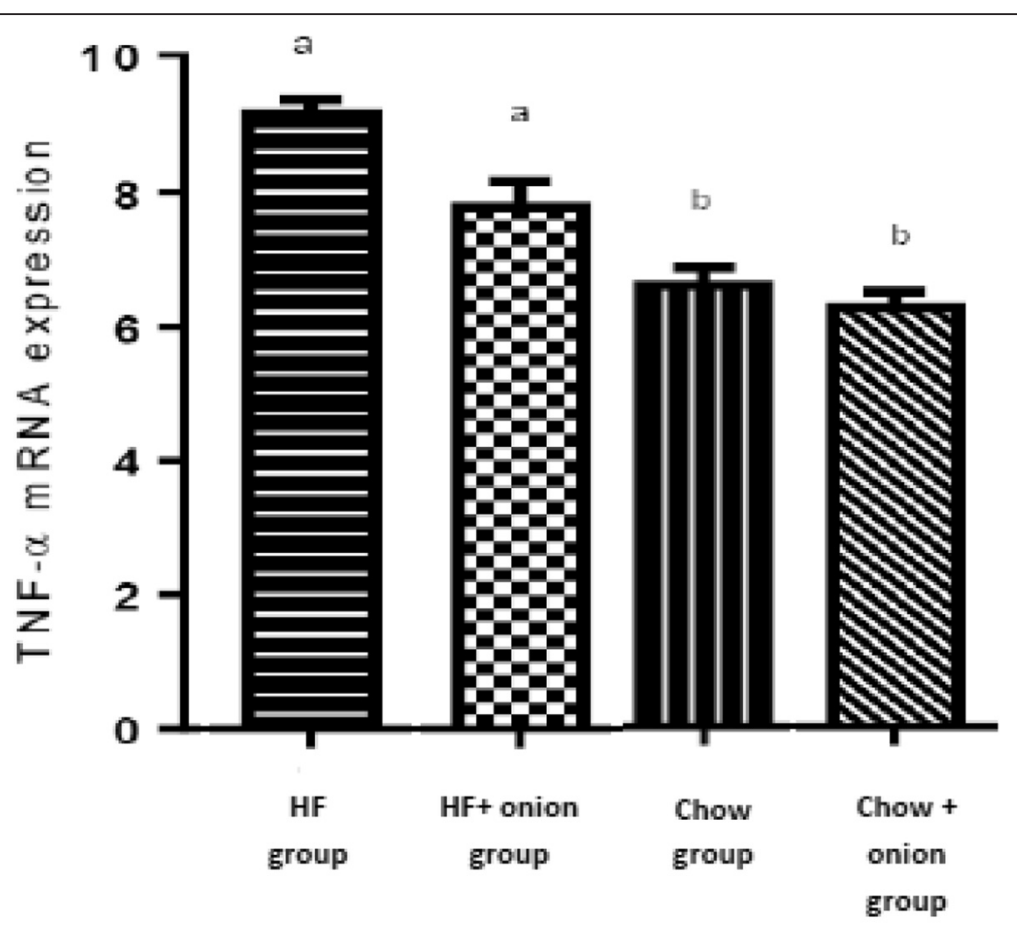

\section{Animal groups}

Fig. 3 Hepatic TNF-a m RNA expression comparison among four groups. Different scripts show significant difference

Table 2 Histopathological characteristics of HF, control, HF + onion and control + onion groups ( $n=6$ in each group)

\begin{tabular}{|c|c|c|c|c|}
\hline & \multirow[t]{2}{*}{ Group } & \multicolumn{2}{|l|}{ Stage } & \multirow[t]{2}{*}{$P$ value } \\
\hline & & Low & High & \\
\hline Steatosis & Control & $6(100)$ & 0 & 0.06 \\
\hline \multirow[t]{3}{*}{ n (\%) } & $\mathrm{HF}$ & $3(50)$ & $3(50)$ & \\
\hline & $\mathrm{HF}+$ onion & $5(83.3)$ & $1(16.7)$ & \\
\hline & Control + onion & $6(100)$ & 0 & \\
\hline Ballooning & Control & $3(50)$ & $3(50)$ & 0.3 \\
\hline \multirow[t]{3}{*}{ n (\%) } & $\mathrm{HF}$ & $1(16.7)$ & $5(83.3)$ & \\
\hline & $\mathrm{HF}+$ onion & $4(66.7)$ & $2(33.3)$ & \\
\hline & Control + onion & $3(50)$ & $3(50)$ & \\
\hline Lobular inflammation & Control & $5(83.3)$ & $1(16.7)$ & 0.5 \\
\hline \multirow[t]{3}{*}{ n (\%) } & $\mathrm{HF}$ & $3(50)$ & $3(50)$ & \\
\hline & $\mathrm{HF}+$ onion & $4(66.7)$ & $2(33.3)$ & \\
\hline & Control + onion & $5(83.3)$ & $1(16.7)$ & \\
\hline Portal inflammation & Control & $4(66.7)$ & $2(33.3)$ & 0.5 \\
\hline \multirow[t]{3}{*}{ n (\%) } & HF & $3(50)$ & $3(50)$ & \\
\hline & $\mathrm{HF}+$ onion & $3(50)$ & $3(50)$ & \\
\hline & Control + onion & $5(83.3)$ & $1(16.7)$ & \\
\hline
\end{tabular}

Low $=0$ or 1 stage

High $=2$ or 3 stage

$H F$ high fat were examined enzymatically all by using a commercial kit (Parsazmoon, Tehran, Iran).

\section{Histopathology}

Five sections from different lobes of each liver were submitted and processed through ethyl alcohol and xylene series, and embedded in paraffine blocks. Slides were stained with Hematoxylin and Eosin and Masson's Trichome and viewed under light microscopy by Nikon E 200. The grading was defined as follow: for hepatic steatosis: grade 0 , no fat; grade 1 , steatosis occupying less than $33 \%$ of the hepatic parenchyma; grade 2, 34$66 \%$ of the hepatic parenchyma; grade 3, more than $66 \%$ of the hepatic parenchyma; for inflammatory cell infiltration: grade 0: none; grade 1, 1-2 foci/field; grade 2, 3-4 foci/field; grade 3, more than 4 foci/field [20]; for ballooning: minimal, mild, and marked [21].

\section{Statistical analysis}

Results are expressed as median (interquartile range) and using nonparametric tests included Mann Whitney, Kruskal Wallis and chi-square tests. $P<0.05$ was considered for significance level. All statistical analyses were performed with the use of either GraphPad Prism Software Version 5.00 (GraphPad Software, SanDiego, CA), or SPSS 20.0 software (Chicago, IL, USA). The raw data are shown in Additional file 1. 


\section{Results}

Weight gain was measured and compared between four groups in beginning, second and fourth weeks of treatment phase (Fig. 1). Weight gain was statistically different between four groups $(P<0.05)$. Weight gain was significantly more in control + onion group than the other three groups $(P<0.05)$. Also, HF group weight gain was more than control group $(P=0.002)$. Other differences were not statistically significant between groups.

Figure 2 shows the food intakes of different groups during the study. Kruskal-Wallis test showed that food intake was significantly different among four groups in every week $(P<0.01)$. Food intake was significantly more in control + onion group than other three groups $(P<0.01)$. Food intake in control group was less than food intake in model group and $\mathrm{HF}+$ onion groups $(P<0.01)$.No difference was seen between $\mathrm{HF}$ and $\mathrm{HF}+$ onion group in food intake.

Table 1 shows the plasma levels of hepatic enzymes, glycemic, and lipid profile in the four groups at the end of the study. HF group had significantly higher plasma level of AST $(P=0.05)$,TG $(P=0.01)$, glucose $(P=0.02)$, cholesterol $(P=0.04)$ and ALP $(P=0.004)$ compared with control group. Adding onion to control group decreased ALT in comparison with $\operatorname{HF} \operatorname{group}(P=0.02)$. Control and control + onion groups were similar except in TG that was less in control + onion compared to control group $(P=0.02)$. Adding onion to HF diet could not cause any significant changes as compared with HF diet.

Hepatic TNF- $\alpha$ gene expression was not significantly decreased in $\mathrm{HF}+$ onion group in comparison to HF group. Treatment by chow or chow + onion could significantly reduce hepatic TNF- $\alpha$ gene expression $(\mathrm{P}<0.05)$ (Fig. 3).

As shown in Table 2 and Fig. 4, no significant difference was seen among four groups in hepatologic indices (steatosis, ballooning, lobular inflammation and portal inflammation) after four weeks of treatment.

\section{Discussion}

Our results have shown that onion consumption can attenuate the risk factors of NAFLD; however, these effects were not statistically significant without accompanying with a healthy diet. Onion can ameliorate the lipid profile, glycemic, and inflammatory indices through its antioxidant, anti-inflammatory, hypoglycemic and hypolipidemic effects [16, 22-26], but these improvements were not statistically different from control group because the animals who consumed onion, their food intake and weight gain were more than those without onion supplementation. Since body weight plays a pivotal role in the pathogenesis
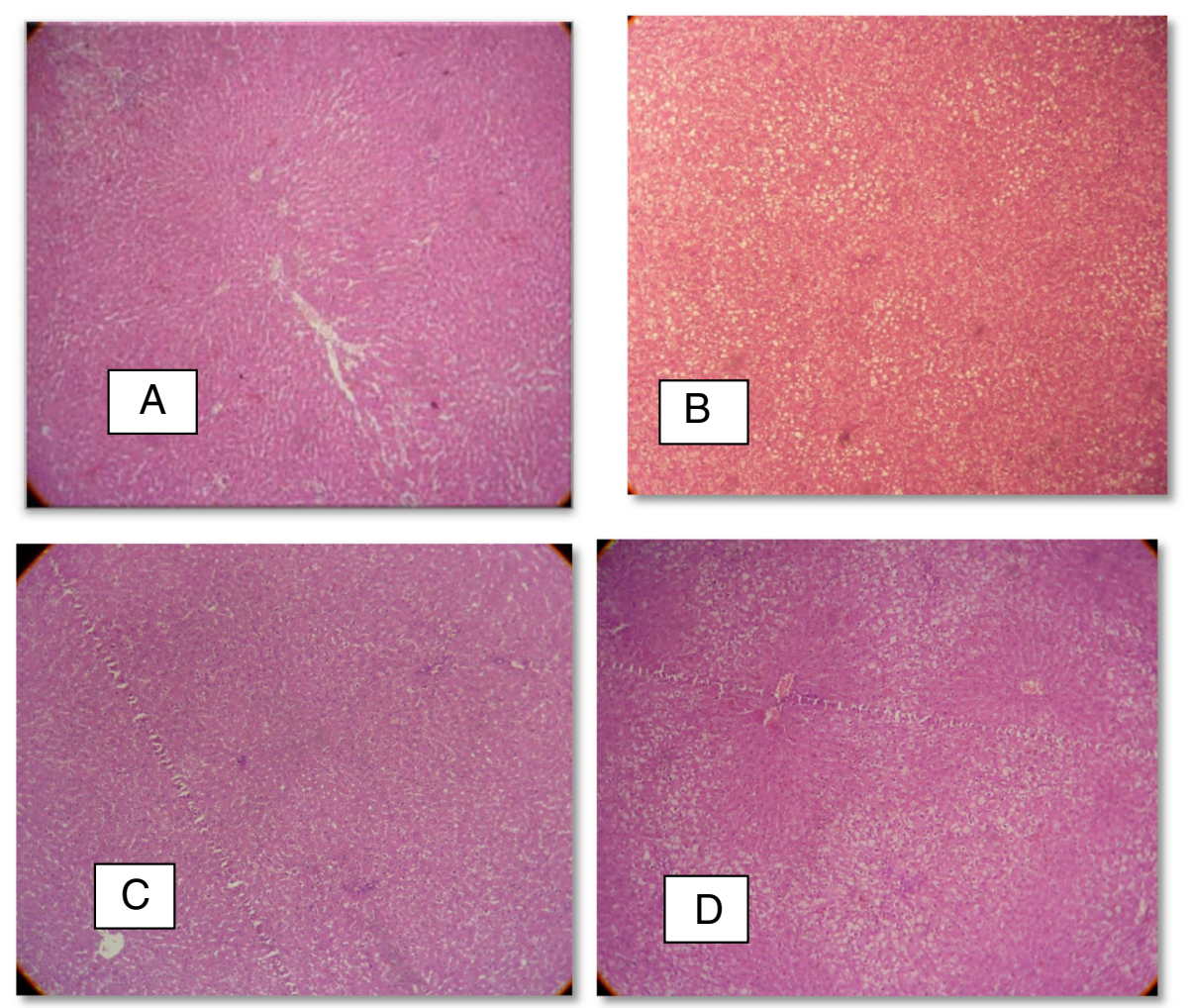

Fig. 4 Hepatic pathology in rats fed control $+7 \%$ onion $\times 100$ (a) fed high fat, high sugar diets ad libitum $\times 100$ (b) fed chow diet ad libitum $\times$ 100 (c) and fed high fat, high sugar diets $+7 \%$ onion $\times 100$ (d). The liver samples were stained with Hematoxylin and Eosin 
of NAFLD [5], it is possible that those animals who received onion, liked its taste and ate more foods, resulting to more weight gain so that the beneficial effects of onion were weakened due to the adverse effects of high food consumption and weight gain.

The animals in control groups whom fed the chow diet with or without onion had significantly lower plasma levels of hepatic enzymes, glycemic and lipid indices, and hepatic TNF- $\alpha$ gene expression, which confirms the pivotal role of diet and weight in the NAFLD management [5]. The effects of onion on the growth performance and appetite enhancement have been shown previously $[27,28]$; however, some of its components act inversely and reduce the body weight [29]. Our results confirm that the whole onion can be used as a growth promoter; however, some of its components may have anti obesity properties.

\section{Conclusion}

In conclusion, our results indicate that adding onion to the diet increases the dietary intakes and weight gain, which contradicts its antioxidant, anti-inflammatory, hypoglycemic and hypolipidemic effects in NAFLD management. Thus, onion consumption can help in NAFLD management when it is combined with a healthy diet. Further studies are needed to explorethe effects of different types of onion on NAFLD management.

\section{Additional file}

Additional file 1: The raw data. (XLS $96 \mathrm{~kb}$ )

\section{Abbreviations \\ ALP, alkaline phosphatase; ALT, alanine aminotransferase; AST, aspartate aminotransferase; GGT, gamma glutamine transferase; HDL-C, high density lipoprotein cholesterol; HF diet, high fat diet; IQR, interquartile range; LDL-C, low density lipoprotein cholesterol; NAFLD, non-alcoholic fatty liver disease; $\mathrm{TG}$, triglyceride}

\section{Acknowledgement}

We sincerely appreciate the cooperation of all staffs in animal lab of NNFTRI, specially Ms. Fazeli, and Ms. Shahraz for their kindly assistance in this project.

\section{Funding}

This study was supported by a grant (No: 568) from Food Technology Research Institute (NNFTRI).

\section{Availability of data and materials}

The dataset supporting the conclusions of this article is included within the article Additional file 1

\section{Authors' contributions}

$\mathrm{AH}$ : had full access to all of the data in the study and took responsibility for the integrity of the data, and the accuracy of the data analysis; $\mathrm{HE}, \mathrm{AH}$, and MT: conceived and designed the study and provided administrative, technical, or material support; $\mathrm{HE}, \mathrm{HE}-\mathrm{Z}$, and $\mathrm{AH}$ : analyzed and interpreted the data; $\mathrm{HE}$ and $\mathrm{AH}$ : drafted the manuscript; All authors: critically revised the manuscript for important intellectual content; $\mathrm{HE}, \mathrm{MR}$, and FF: conducted the study; and AH: obtained funding and supervised the study. None of the authors had any conflict of interest. All authors read and approved the final manuscript.

\section{Competing interests}

The authors declare that they have no competing interests.

\section{Consent for publication}

Not applicable.

\section{Ethics approval and consent to participate}

All animal procedures were carried out in accordance with the National Nutrition and Food Technology Research Institute (NNFTRI). The study protocol was approved at NNFTRI ethics committee with ethics code of NNFTRI 1393-568

\section{Author details}

${ }^{1}$ Department of Clinical Nutrition and Dietetics, Faculty of Nutrition Sciences and Food Technology, National Nutrition and Food Technology Research Institute, Shahid Beheshti University of Medical Sciences, Tehran, Iran. ${ }^{2}$ Department of Pathology, Taleghani Hospital, Faculty of Medicine, Shahid Beheshti University of Medical Sciences, Tehran, Iran. ${ }^{3}$ Research Center for Biochemistry and Nutrition in Metabolic Diseases, Kashan University of Medical Sciences, Kashan, Iran

Received: 21 April 2016 Accepted: 14 July 2016

Published online: 22 July 2016

\section{References}

1. Chalasani $\mathrm{N}$, et al. The diagnosis and management of non-alcoholic fatty liver disease: practice guideline by the American association for the study of liver diseases, American college of gastroenterology, and the American gastroenterological association. Hepatology. 2012;55(6):2005-23.

2. Chang E, Park CY, Park SW. Role of thiazolidinediones, insulin sensitizers, in non-alcoholic fatty liver disease. J Diabetes Investig. 2013;4(6):517-24

3. Eslamparast $T$, et al. Synbiotic supplementation in nonalcoholic fatty liver disease: a randomized, double-blind, placebo-controlled pilot study. Am J Clin Nutr. 2014;99(3):535-42.

4. Faghihzadeh F, Adibi $P$, Hekmatdoost A. The effects of resveratrol supplementation on cardiovascular risk factors in patients with non-alcoholic fatty liver disease: a randomised, double-blind, placebo-controlled study. Br J Nutr. 2015;114(5):796-803.

5. Ghaemi A, et al. How much weight loss is effective on nonalcoholic fatty liver disease? Hepat Mon. 2013;13(12):e15227.

6. Askari F, Rashidkhani B, Hekmatdoost A. Cinnamon may have therapeutic benefits on lipid profile, liver enzymes, insulin resistance, and highsensitivity C-reactive protein in nonalcoholic fatty liver disease patients. Nutr Res. 2014;34(2):143-8.

7. Faghihzadeh F, et al. Resveratrol supplementation improves inflammatory biomarkers in patients with nonalcoholic fatty liver disease. Nutr Res. 2014; 34(10):837-43.

8. Eslamparast $\mathrm{T}$, et al. Recent advances in dietary supplementation, in treating non-alcoholic fatty liver disease. World J Hepatol. 2015;7(2):204-12.

9. Rahimlou M, Ahmadnia H, Hekmatdoost A. Dietary supplements and pediatric non-alcoholic fatty liver disease: present and the future. World J Hepatol. 2015;7(25):2597-602.

10. Hardy T, Anstee QM, Day CP. Nonalcoholic fatty liver disease: new treatments. Curr Opin Gastroenterol. 2015;31(3):175-83.

11. Liao YR, Lin JY. Quercetin intraperitoneal administration ameliorates lipopolysaccharide-induced systemic inflammation in mice. Life Sci. 2015; 137:89-97.

12. Alam MM, Meerza D, Naseem I. Protective effect of quercetin on hyperglycemia, oxidative stress and DNA damage in alloxan induced type 2 diabetic mice. Life Sci. 2014;109(1):8-14.

13. Slimestad R, Fossen T, Vagen IM. Onions: a source of unique dietary flavonoids. J Agric Food Chem. 2007;55(25):10067-80.

14. Adesso $\mathrm{S}$, et al. Anti-inflammatory and anti-oxidant activity of polyphenolic extracts from Lactuca sativa (var. Maravilla de Verano) under different farming methods. J Sci Food Agric. 2016. doi: 10.1002/jsfa.7622. [Epub ahead of print].

15. Emamat $\mathrm{H}$, et al. An accessible and pragmatic experimental model of nonalcoholic fatty liver disease. Middle East J Dig Dis. 2016;8(2):1-7.

16. Hamauzu Y, et al. Physicochemical characteristics of rapidly dried onion powder and its anti-atherogenic effect on rats fed high-fat diet. Food Chem. 2011;129(3):810-5. 
17. Ackerman Z, et al. Fructose-induced fatty liver disease: hepatic effects of blood pressure and plasma triglyceride reduction. Hypertension. 2005;45(5): 1012-8.

18. Dhibi $\mathrm{M}$, et al. The intake of high fat diet with different trans fatty acid levels differentially induces oxidative stress and non alcoholic fatty liver disease (NAFLD) in rats. Nutr Metab (Lond). 2011;8(1):65.

19. Safwat $G M$, et al. Induction of non-alcoholic fatty liver disease and insulin resistance by feeding a high-fat diet in rats: does coenzyme Q monomethyl ether have a modulatory effect? Nutrition. 2009;25(11-12):1157-68.

20. Xu ZJ, et al. Characterization of high-fat, diet-induced, non-alcoholic steatohepatitis with fibrosis in rats. Dig Dis Sci. 2010;55(4):931-40.

21. Brunt EM, et al. Nonalcoholic steatohepatitis: a proposal for grading and staging the histological lesions. Am J Gastroenterol. 1999;94(9):2467-74.

22. Jaiswal N, Rizvi Sl. Onion extract (Allium cepa L.), quercetin and catechin up-regulate paraoxonase 1 activity with concomitant protection against low-density lipoprotein oxidation in male Wistar rats subjected to oxidative stress. J Sci Food Agric. 2014;94(13):2752-7.

23. Wang BS, et al. Anti-inflammatory effects of an aqueous extract of Welsh onion green leaves in mice. Food Chem. 2013;138(2-3):751-6.

24. Lee $B$, Jung JH, Kim HS. Assessment of red onion on antioxidant activity in rat. Food Chem Toxicol. 2012;50(11):3912-9.

25. Jung JY, et al. Onion peel extracts ameliorate hyperglycemia and insulin resistance in high fat diet/streptozotocin-induced diabetic rats. Nutr Metab (Lond). 2011;8(1):18.

26. Vidyavati $\mathrm{HG}$, et al. Hypolipidemic and antioxidant efficacy of dehydrated onion in experimental rats. J Food Sci Technol. 2010:47(1):55-60.

27. An BK, et al. Effects of onion extracts on growth performance, carcass characteristics and blood profiles of white mini broilers. Asian-Australas J Anim Sci. 2015;28(2):247-51.

28. Jatzlau A, et al. Nature helps: food addition of micronized coconut and onion reduced worm load in horses and sheep and increased body weight in sheep. Parasitol Res. 2014;113(1):305-10.

29. Kook S, Kim GH, Choi K. The antidiabetic effect of onion and garlic in experimental diabetic rats: meta-analysis. J Med Food. 2009;12(3):552-60.

\section{Submit your next manuscript to BioMed Central and we will help you at every step:}

- We accept pre-submission inquiries

- Our selector tool helps you to find the most relevant journal

- We provide round the clock customer support

- Convenient online submission

- Thorough peer review

- Inclusion in PubMed and all major indexing services

- Maximum visibility for your research

Submit your manuscript at www biomedcentral.com/submit

) Biomed Central 